\section{Estudo \\ CoDebate}

em Cestão

Plamejamento
Revista Estudo \& Debate, Lajeado, v. 26, n. 4, 2019. ISSN 1983-036X

DOI: http://dx.doi.org/10.22410/issn.1983-036X.v26i4a2019.2206

\title{
O IMPACTO DOS CICLOS POLÍTICOS NOS RETORNOS E NA VOLATILIDADE DO IBOVESPA
}

\author{
André Locatelli ${ }^{1}$, Carlos Eduardo Lobo e Silva ${ }^{2}$, Augusto Mussi Alvim³
}

\begin{abstract}
Resumo: O presente artigo tem como objetivo investigar se os ciclos políticos influenciam os retornos e a volatilidade do Ibovespa, índice da bolsa de São Paulo. Os dados utilizados serão os retornos diários do Ibovespa e os retornos diários do S\&P 500, um dos principais índices do mercado acionário norte americano e que servirá para captar as mudanças do mercado acionário externo. Para calcular a influência dos ciclos políticos econômicos sobre os retornos e a volatilidade do Ibovespa foi utilizado o modelo econométrico GARCH, que tem sido amplamente utilizado em trabalhos dessa natureza, e que tem se demonstrado consistente na estimação de séries temporais. Os resultados encontrados reforçam as conclusôes de estudos da literatura para diversos países: enquanto os retornos nấo são afetados significativamente, é possível detectar efeitos na volatilidade do índice em períodos próximos às eleiçôes nacionais. Nossos resultados sugerem que a volatilidade mais significativa ocorre no período entre 150 e 60 dias antes do pleito e se dissipa nos últimos dois meses, quando os candidatos já estão formalmente definidos.
\end{abstract}

Palavras-chave: Ciclos Políticos, Ibovespa, Modelo GARCH.

\section{THE IMPACT OF ECONOMIC POLICY CYCLES ON IBOVESPA RETURNS AND VOLATILITY}

\begin{abstract}
This article aims to investigate if the political cycles influence the returns and the volatility of the Ibovespa, stock market index of São Paulo. The data used will be the daily returns of the Ibovespa and the daily returns of the S \& P 500, one of the main indices of the North American stock market and that will serve to capture the changes of the external stock market. To calculate the influence of economic policy cycles on Ibovespa returns and volatility, the GARCH econometric model was used, which has been widely used in this type of work and has been shown to be consistent in the estimation of time series. The results support the conclusions of studies in the literature for several countries: while returns are not significantly affected, it is possible to detect effects on the volatility of the index in periods close to the national elections. Our results suggest that the most significant volatility occurs in the period between 150 and 60 days before the election and dissipates in the last two months, when the candidates are already formally defined.
\end{abstract}

Keywords: Political Business Cycles, Ibovespa Index, GARCH Models.

JEL: C12, G14, E32, E44

1 Doutorando em Economia Internacional pela Universidade do Rio dos Sinos - UNISINOS.

2 Pós Doutor em Economia; Professor da Pontifícia Universidade Católica do Rio Grande do Sul.

3 Pós Doutor em Economia; Professor da Pontifícia Universidade Católica do Rio Grande do Sul. 


\section{Introdução}

Os eventos econômicos são diretamente influenciados pelas decisóes políticas e pelas eleições de um país, principalmente as presidenciais. No Brasil temos eleiçôes presidenciais a cada quatro anos e isso muitas vezes gera uma incerteza em relaçáo à continuidade das políticas adotadas por governantes anteriores. Nos Estados Unidos, dependendo do partido vitorioso, a bolsa e/ou os títulos públicos podem sofrer ganhos ou perdas significativas, conforme estudo realizado por Hensel e Ziemba (1995). Os autores mostram que a expectativa quanto ao partido que vencerá as eleiçóes pode impactar as taxas de juros, de desemprego, de câmbio, de investimentos e nos gastos governamentais e subsídios concedidos. No mesmo sentido Pástor e Veronesi (2017) concluem que, dependendo do partido que estiver mais próximo da vitória das eleições presidenciais, trará reflexos positivos ou negativos no preço das açóes negociadas em bolsa.

De forma geral, os ciclos de negócios são frequentemente impactados pela agenda eleitoral. Variáveis econômicas como, por exemplo, investimentos, inflação, taxas de juros, taxas de câmbio, gastos do governo, entre outros, são impactados diretamente nos períodos eleitorais. Por um lado, a teoria dos mercados eficientes nos diz que os ativos financeiros são precificados a todo instante, levando em consideração os eventos passados e futuros. Sendo assim, não haveria maiores surpresas durante as fases eleitorais, pois o mercado já haveria antecipado os prováveis resultados de uma eleiçáo, não havendo retornos acima da média no mercado, em função do cenário político. Por outro lado, a teoria dos ciclos políticos, desenvolvida por William Nordhaus (1975) mostra que há influência dos atos dos governantes nas variáveis econômicas, pois os mesmos usam anos eleitorais para aumentar gastos e promover um crescimento econômico, ainda que de curto prazo.

Inserido neste contexto, o objetivo do presente trabalho é verificar se as açóes da bolsa brasileira sofrem impactos em decorrência dos ciclos políticos. Para atingir tal objetivo é avaliado se o retorno médio e a volatilidade do Ibovespa sofrem alteraçóes nos períodos pré-eleitorais.

O tema do presente artigo tem sido pouco explorado pela literatura nacional e seus resultados permitem não apenas identificar efeitos sobre o Ibovespa, mas também a comparação com os resultados da literatura internacional para outros países. Mais especificamente, o impacto sobre a volatilidade encontrado, sem efeitos significativos sobre o retorno das açóes, coincide com os resultados de Siokis e Kapopoulos (2007), Azevedo (2012) e Koksal e Caliskan (2012), que estudaram os mercados financeiros, respectivamente, de Grécia, Portugal e Turquia e Myataza e Gupta (2018) que estudaram os efeitos causados pelos ciclos políticos dos Estados Unidos na volatilidade e nos retornos dos países de economia avançada, sendo eles o Canadá, França, Alemanha, Itália, Japão Suíça e Reino Unido.

\section{Teorias de Ciclo Político Econômico}

Dentre as teorias sobre ciclos políticos, a mais conhecida, e a primeira a ser apresentada, é a Political Business Cycle criada por Norhaus (1975) e diz que os governantes tendem a escolher uma combinação de desemprego e inflação ao longo da curva de Phillips antes 
das eleições, visando enganar sistematicamente os eleitores em períodos pré-eleitorais. Seu estudo, realizado em 1975 e chamado de Teoria Oportunista Tradicional, nos mostra que os governantes ao longo de seus mandatos agem de forma oportunista apenas para maximizar suas votaçóes, ignorando sua ideologia e as orientaçóes do partido. As suas decisóes políticas visariam apenas à manutenção do poder, sem levar em conta o interesse público. Nordhaus (1975) defendia a ideia de que os governantes iriam estimular a demanda agregada em períodos pré-eleitorais com o intuito de aumentar a taxa de crescimento econômico e diminuir a taxa de desemprego através de uma política monetária expansionista e assim se beneficiar com tais resultados nas eleiçóes. Passadas as eleiçóes, o governante adotaria novamente medidas de política monetária contracionista, trazendo a inflação a patamares desejados o que acarretaria num aumento do desemprego, provavelmente a taxas similares às anteriores a eleição.

Na formulação da Teoria Partidária Tradicional, um dos autores mais reconhecidos foi Hibbs (1977) que formulou um modelo que mede a diferença dos partidos no que diz respeito à condução de política econômica e dos resultados macroeconômicos dos Estados Unidos e Inglaterra. Os modelos tradicionais assumem que os políticos são iguais entre si e buscam a permanência no poder. Mas como cada partido é composto por um grupo de pessoas que teoricamente compartilham da mesma ideologia, os modelos partidários tradicionais vieram para incorporar este elemento ao estudo dos ciclos políticos. $\mathrm{O}$ trabalho de Hibbs (1977) possui uma abordagem empírica, sendo assim, não apresenta uma modelagem teórica formal de sua hipótese. Mesmo assim a sua linha de raciocínio segue a da Teoria Oportunista Tradicional aonde se utilizam da curva de Phillips com expectativas adaptativas para explicar seu modelo de sistema econômico em que os policymakers possuem controle total sobre as ferramentas de política econômica.

Com a criação da teoria das expectativas racionais, perdeu-se a premissa utilizada pelos ciclos políticos oportunistas que dizia que os eleitores eram ingênuos, incapazes de aprender, e propensos a erros sistemáticos, com isso criou-se a Teoria Partidária Racional. Alesina (1988) reformulou os modelos partidários tradicionais e partiu do princípio de que processos eleitorais equitativos têm como particularidade a incerteza quanto ao resultado das urnas. Nos anos de eleiçôes, mesmo que os eleitores tenham expectativas racionais, não saberão qual partido estará governando no ano seguinte e logo, qual política econômica será adotada. Em uma economia com expectativas racionais, as políticas econômicas adotadas somente terão efeitos reais sobre a economia se surpreenderem os agentes econômicos. Houve uma reformulação das teorias dos ciclos políticos econômicos incluindo a teoria das expectativas racionais. A tese da teoria racional é de que os eleitores, ao ter passado por um ciclo político anterior, não seriam mais enganados pelos governantes, pois eles sabem que em períodos eleitorais os governantes aumentam os gastos para promover crescimento na atividade econômica e logo após as eleiçôes ele utiliza uma política econômica contracionista.

Já a teoria oportunista racional foi criada por Rogoff e Sibert (1988) com o intuito de conciliar os modelos oportunistas ao modelo de expectativas racionais. Para esses modelos os ciclos políticos econômicos existem devido à assimetria de informaçóes entre os eleitores e os políticos, pois os primeiros náo têm elementos para quantificar o grau de competência dos segundos, quando de posse de um cargo eletivo. Os governantes procuram administrar 
a máquina pública de uma forma aparentemente competente aos olhos dos eleitores, já que somente o político tem condiçóes de realmente avaliar se está administrando com todo seu potencial. Os eleitores procuram mensurar essa capacidade de administrar através dos dados macroeconômicos. Para corroborar com as expectativas dos eleitores, os governantes tentam gerir a máquina pública de forma mais competente possível, o que cria os ciclos políticos econômicos.

\subsection{Ciclos Político Econômicos em Bolsas de Valores}

Baseados nas teorias dos ciclos político-econômicos, previamente mencionadas, surgem vários estudos ligando tais teorias ao comportamento do mercado financeiro, principalmente no que diz respeito ao comportamento das bolsas de valores. Segundo Azevedo (2012), o primeiro trabalho nessa área foi de Niederhoffer et al. (1970), que analisou os movimentos diários e semanais da bolsa de valores Americana, em períodos de eleiçôes presidenciais. Azevedo (2012) divide o conjunto bibliográfico sobre o tema em três grupos, baseados em três diferentes resultados.

$\mathrm{O}$ primeiro grupo de pesquisa analisa a reação imediata do mercado à eleição presidencial, onde é colocada à prova a ideia tradicional do mercado financeiro americano de que os agentes preferem os candidatos Republicanos. Niederhoffer et al. (1970) e Riley et al. (1980) corroboram com essa linha de pesquisa e comprovam que nos dias e semanas que seguem o resultado das urnas, há uma resposta positiva em relação à vitória de um candidato Republicano: os estudos mostram retornos maiores com a vitória Republicana em comparação a uma vitória do partido Democrata.

Niederhoffer et al. (1970) utilizou como referência para corroborar sua teoria os dados de 18 eleiçóes entre 1900 e 1968, levando em conta a variaçáo da bolsa de Nova York uma semana antes, um dia antes, um dia após e uma semana após a realização do pleito. Quando apurado os dados do dia após as eleiçóes ele encontrou para as vitórias do Partido Republicano 8 altas no Dow Jones e 1 queda. Quando se trata de vitórias do Partido Democrata foram encontradas 4 altas e 5 quedas, no total de 18 eleiçóes. A média na variação do índice, um dia após as eleiçóes, foi de $+1,12 \%$ para as vitórias Republicanas e $-0,81 \%$ para vitórias Democratas. Já a variação mensal foi de $+1,30 \%$ para vitórias Republicanas e $-1,13 \%$ para vitórias Democratas. A variação média ocorrida após os resultados foi de $1,08 \%$ para as vitórias Republicanas e $-0,23 \%$ para vitórias Democratas.

O trabalho de Riley et al. (1980), chamado "The Market Prefer Republicans: Mith or Reality", inicia com uma crítica ao trabalho anterior feito por Niederhoffer et al. (1970). Segundo o autor, no trabalho anterior não foi feita uma tentativa de reconhecer e apurar tendências, lucros de negociação e nem avaliação de risco para se chegar a uma conclusão de que o mercado financeiro prefere vitórias do Partido Republicano. O mesmo afirma que as bases empíricas para se chegar a essa conclusão são, na melhor das hipóteses, fracas. $\mathrm{O}$ autor começa explicando a teoria das expectativas racionais de Eugene Fama, que diz que os mercados estão ajustados levando em consideração eventos passados e as probabilidades dos eventos futuros. Os preços automaticamente se adaptam às novas informaçóes. Riley et al. (1980) testaram 20 subperíodos em torno das eleiçóes presidenciais americanas entre 1900 e 1976, testando atraso nas respostas nos ajustes dos preços dos ativos da bolsa de Nova 
York. Utilizando o método dos mínimos quadrados ordinários, se obteve uma regressão

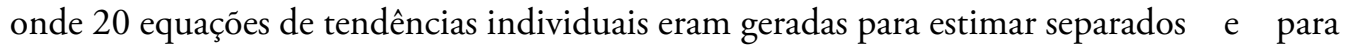
cada período eleitoral. Uma vez obtidos os coeficientes, eram usados para gerar valores previsíveis para primeira diferença em logaritmo natural dos preços para cada dia das 17 semanas que giravam em torno das eleiçóes. A conclusão que o autor chega é que realmente o mercado prefere o Partido Republicano, pelo menos no curto prazo.

O segundo grupo, proposto por Azevedo (2012), estuda o efeito dos partidos Republicanos e Democratas em relação ao comportamento dos indicadores financeiros durante o mandato presidencial e verifica qual o partido que gera maiores retornos ao mercado, o que demonstraria a preferência dos agentes econômicos. $\mathrm{O}$ estudo realizado por Huang (1985) refuta os resultados prévios que diziam que os retornos do mercado eram maiores com os Republicanos no governo e demonstra que durante a gestáo dos Democratas os retornos dos ativos são maiores. Para provar isso o autor sintetiza em tabelas os retornos do mercado de açóes nos primeiros, segundos, terceiros e quartos anos de governos, de forma individual, demonstrando que nos primeiros e segundos anos de mandatos presidenciais os retornos em títulos públicos são, em média, maiores que os retornos em açóes. Nos terceiros e quartos anos os retornos em açóes são, em média, maiores que os retornos em títulos públicos. Especialmente em mandatos de presidentes Democratas os retornos em ações são, em média, maiores do que os retornos médios em períodos em que os Republicanos estáo no poder. Com isso ele afirma que é infundada a tese de que o mercado financeiro prefere presidentes de partidos Republicanos por ser um partido voltado ao mercado.

Hensel e Ziemba (1995) estudaram os retornos dos ativos do mercado financeiro americano no período entre 1928 e 1993. Os autores não encontraram diferenças estatisticamente significativas entre os retornos dos ativos, comparando as administraçóes dos dois partidos no que diz respeito ao índice Standard and Poor's (S\&P500), mas constataram que há maiores retornos nas açóes de pequenas empresas (small-capitalization stocks) nas administraçôes Democratas em relação às administrações Republicanas. Tanto as ações de pequenas empresas quanto de grandes empresas tiveram retornos significativamente maiores nos terceiros e quartos anos de mandatos, independente do partido que estava no poder.

O terceiro grupo aborda os ciclos de dois e quatro anos dos mercados financeiros nos Estados Unidos. O trabalho de Allvine e O'Neill (1980) comprova a existência de uma tendência cíclica, repetindo-se de quatro em quatro anos e que respeita a agenda eleitoral, de forma que são dados estímulos econômicos próximos às eleiçóes presidenciais, continuando com medidas inflacionárias após o término das eleiçóes. Os ciclos de quatro anos somamse com os ciclos de dois anos e são chamados de "efeito segunda parte". Esse efeito surge devido aos estímulos econômicos dados nos últimos dois anos do mandato e que resulta num melhor desempenho da economia, se comparado com os dois primeiros anos. Os pesquisadores afirmam que a diferença dos retornos das açóes entre a primeira e a segunda parte do mandato é estatística e economicamente significativa. Os dados do trabalho se concentraram em ciclos de 26 semanas até 416 semanas, analisando as cotaçôes do índice da bolsa americana S\&P 500. Os resultados obtidos, com um nível de significância de $95 \%$, é que há ciclos no período compreendido entre 208 semanas e que vale a pena ser 
explorado. Também foram encontrados ciclos em outros períodos, mas não estatisticamente significativos.

Em outro artigo baseado nos EUA, Pástor e Veronesi (2017) desenvolveram um modelo de ciclos políticos na qual o problema de decisão presidencial surge de forma endógena. Os autores constataram que, quando a aversão ao risco é alta, os eleitores estão mais propensos a votar em um candidato democrata porque necessitam de mais seguro social. Por outro lado, quando a aversão ao risco é baixa, é crível que um candidato republicano seja eleito porque os eleitores têm mais tolerância ao risco. Assim, em função de uma maior aversão ao risco gerada pela possível vitória de um candidato democrata, sugere que os investidores querem ser compensados com retornos médios mais altos no mercado de açóes.

Se tratando dos efeitos das eleições americanas nas bolsas de outros países, o estudo formulado por Foerster e Schmitz (1997) analisa os retornos das bolsas de valores de 18 países da OCDE e que confirma a existência de um ciclo de quatro anos, estatisticamente significativo, correlacionado com a agenda das eleiçóes americanas. O período utilizado foi entre 1957 e 1996, utilizando as variaçóes mensais dos índices de açóes dos países estudados. Os autores verificaram que nos anos 1, 3 e 4 após as eleiçóes americanas, a rentabilidade média das açôes desses países foi de $11,68 \%$ e no ano 2 a rentabilidade média foi de $-0,66 \%$, comprovando, segundos os autores, que as eleiçóes americanas influenciam os ciclos políticos econômicos dos demais países estudados. Essa rentabilidade negativa no ano 2 se apresentou robusta em testes paramétricos e não paramétricos. Nas regressóes calculadas, utilizando como proxy variáveis macroeconômicas da economia americana e como dummy o ano 2 das eleiçóes americanas, sendo que a variável eleiçóes americanas teve um peso significativo na regressáo.

Na mesma linha de estudo Myataza e Gupta (2018) investigaram os efeitos que os ciclos políticos dos Estados Unidos causam na volatilidade e nos retornos dos mercados de ações em países com economias avançadas tais como Canadá, França, Alemanha, Itália, Japão Suíça e Reino Unido. Para isso, utilizaram dados mensais dos retornos dos índices acionários dos países citados mensurados com o modelo EGARCH $(1,1)$. Os resultados encontrados indicam que, quando um presidente do partido Democrata se encontra no poder, há um aumento na volatilidade e nos retornos dos índices acionários dos países estudados. Isso ocorre, pois, os candidatos Democratas representam maiores riscos ao mercado e os investidores, que possuem aversão ao risco, precisam ser compensados com retornos maiores.

Quando saímos das análises em torno das eleições americanas, temos o estudo feito por Pantzalis e Turtle (2000) que analisaram 33 países da OCDE e demonstraram que nas duas semanas próximas às eleiçóes presidenciais desses países, entre 1974 e 1995, se observa um aumento da volatilidade e dos retornos dos índices das suas respectivas bolsas de valores, comprovando a influência dos ciclos políticos no mercado financeiro. Em particular foram encontrados retornos anormais nas situaçóes em que, em países com menor grau de liberdade, a oposição tenha ganhado o pleito e quando ele foi antecipado e perdido pelo partido que a promoveu. Para tal estudo, os autores utilizaram os retornos semanais das bolsas de valores, no período compreendido entre 1974 e 1995, e outros indicadores econômicos, tais como PIB, taxa de desemprego e inflação de cada país que compóe a 
OCDE. Os índices de liberdade econômica, liberdade política e de imprensa compõem um índice específico englobando essas variáveis e foi desenvolvido pela organização não partidária e sem fins lucrativos, chamada Freedom House.

Com relação à bolsa Belga, Vuchelen (2003) faz o estudo relacionando os ciclos políticos daquele país e os efeitos no mercado interno. $\mathrm{O}$ autor apurou uma leve alta nos preços das açóes após uma vitória de uma coligaçáo centro-esquerda e uma diminuição dos mesmos após a eleição de um governo de centro-direita. Para o estudo ele utilizou os dados trimestrais de variação da bolsa de Bruxelas no período entre 1974 e 2000, variação do dólar no trimestre, a variação da bolsa americana, variação das taxas dos títulos públicos no trimestre e a variação do índice de ciclos de negócios formulada pelo banco KBC, além de 3 dummies que assumiam valor 0 e 1 dependendo do partido que era eleito e calculou utilizando regressão linear múltipla. Os resultados mostraram que a variaçáo da bolsa americana tem peso significativo na regressão. Um índice de ciclos de negócios mais alto e uma variação do dólar positiva, também demonstraram impactos positivos nas açóes belgas.

Na Alemanha, Döpke e Pierdzioch (2006) constataram que os ciclos políticos causam um impacto pequeno no índice da bolsa daquele país (DAX), apesar disso, outros dados apurados revelaram que os níveis dos retornos dos ativos afetam diretamente a popularidade do governo. Entretanto, não foi observado que os ciclos políticos teriam algum efeito nos retornos dos ativos financeiros e nem há mudança nos retornos quando partidos de direita ou de esquerda assumem o poder. Foram utilizados dados de questionários sobre a popularidade do governo, aplicado a eleitores e compilados pela "Forschungsgruppe Wable", Mannheim, para estimar a equação onde avalia se a popularidade dos governantes afetam os retornos dos ativos.

No estudo realizado por Siokis e Kapopoulos (2007) foram encontradas evidências de que tanto o partido político que está no poder quanto o período eleitoral trazem efeitos à volatilidade do índice grego, sendo maior no período em que um partido de direita está no poder além de ser maior em períodos pré-eleitorais. Porém essa maior volatilidade não representa maiores retornos nesse caso específico.

Vale mencionar ainda, o estudo de Turquia Köksal e Caliskan (2012) que investigaram a bolsa local e náo encontraram evidências de ciclos político-econômicos nos retornos do índice da bolsa, apenas evidência de aumento na volatilidade dos ativos. Verificaram ainda o aumento da volatilidade antes das eleiçóes, assim como durante os períodos em que um partido de esquerda ou uma coligação está no poder. Observou-se ainda uma diminuição dos retornos no início de um governo de direita e um aumento nos retornos no início de um governo de esquerda. Os dados utilizados foram os logs dos retornos diários, do índice da bolsa de Istanbul, do período compreendido entre 04/01/1988 a 07/07/2011, resultando em 5868 dias de pregão. $\mathrm{O}$ modelo matemático utilizado para calcular as variáveis foi o GARCH. Inicialmente os autores ajustaram o modelo ARMA (p,q) para descobrir onde estava a melhor combinação na qual resultou em ARMA $(1,8)$. Foi incluída a variável percentual dos rendimentos compostos do Índice Standard and Poor's (SP500) com um lag na equação para controlar o efeito da economia global nos retornos do índice da bolsa de Istambul. Para testar a volatilidade, foi inserida na equação uma dummy assumindo valores 1 nos seis meses que antecedem as eleiçóes e 0 nos demais meses. Os resultados 
nas equaçóes de volatilidade para a amostra indicam que a volatilidade do índice da bolsa aumenta um mês antes das eleiçóes gerais. Este comportamento na volatilidade pode ser devido às incertezas associadas com eleiçóes.

Azevedo (2012) investigou a presença de ciclos político-econômicos na bolsa portuguesa para averiguar se os governantes colocavam em prática alguma das quatro correntes da teoria em seus mandatos, para assegurar a reeleição. Utilizando o modelo GARCH $(1,1)$ para estimar os dados do índice da bolsa portuguesa PSI20, no intuito de verificar alguma anormalidade dos retornos e da volatilidade em períodos pré-eleitorais, não foi encontrado evidências de que houvesse influência de ciclos político-econômicos para os retornos, no período compreendido entre 05/01/1993 e 30/12/2011 (4704 observaçóes). $\mathrm{O}$ mesmo não ocorre para volatilidade, onde se encontrou a presença de influência dos ciclos político-econômicos no período estudado. Foi utilizado uma Dummy com valor 1, no período que compreende os 6 meses que antecedem as eleições e o valor 0 nos demais períodos.

Em um estudo realizado por Ramírez, Meza e Martínez (2017) sobre a dependência entre a bolsa mexicana e a taxa de câmbio naquele país e, tendo como parâmetro os ciclos políticos entre 1994 e 2012, os autores detectaram uma relação não linear e bidirecional para qualquer alteração no governo, independente do partido no poder. Foi utilizado o teste não-paramétrico e não-linear de Hinch, uma forma pioneira para estudar séries temporais em mercados emergentes, com o objetivo de investigar qual a relação entre a Bolsa de Valores do México e taxa de câmbio peso/dólar, medida através da correlação crusada entre 1994 e 2012, que engloba três períodos de administração presidencial. Os resultados indicaram uma relação não-linear detectada através de uma significativa bicorrelação cruzada para distintos períodos, entretanto não há significativos períodos com correlação cruzada. As eleiçóes mexicanas ocorrem a cada 6 anos portanto, o período estudado, é relativo à 3 eleiçóes. Os resultados demonstram que os períodos não lineares bidirecionais estavam no início e final do período de seis anos caracterizando a dependência bidirecional entre as oscilaçóes da bolsa mexicana e a taxa de câmbio no início e término de mandatos presidenciais.

\section{Dados e Metodologia}

O Ibovespa é o principal índice da bolsa de valores de São Paulo. Ele é composto pelas 65 açóes de maior liquidez e maior capitalização bursátil. A cada três meses o índice é revisado e os pesos das ações que o compóem são modificados, de acordo com os critérios elegíveis para composição da carteira. Por ser o principal indicador do mercado acionário brasileiro, testa-se aqui se ele sofre influência dos ciclos políticos durante o período de eleições presidenciais.

Para efetuar a análise foram utilizadas as cotaçóes diárias de fechamento do índice bolsa Brasileira (Ibovespa), do período entre 03/01/2000 a 06/05/2015 (3816 observaçóes), fornecidas pela Bovespa através do seu site (www.bmfbovespa.com.br). O período selecionado se justifica em virtude de, até o ano 2000, a Bolsa do Rio de Janeiro ser responsável por um grande volume de negócios, principalmente no tocante à operaçóes de privatização de estatais. Após o ano 2000 o volume da mesma se reduziu de forma significativa, vindo a 
ser incorporada pela BMF em 2002. Para termos uma uniformidade de dados, se optou por eleger o período destacado, onde a bolsa de Sáo Paulo se tornou o principal veículo de referência e negociaçóes de açóes no Brasil.

Uma variável de controle foi introduzida no modelo para acompanhar os movimentos dos mercados internacionais. Seguindo Koksal e Caliskan (2012), selecionou-se aqui o índice S\&P 500, que é composto por 500 empresas americanas, listadas nas bolsas NYSE e NASDAQ, que representam as maiores e mais líquidas açóes listadas naquelas bolsas. Os dados foram obtidos através do site Yahoo Finance (https://finance.yahoo.com).

No presente trabalho é utilizado os retornos do Ibovespa e do S\&P 500, para formatar os dados visando uma menor variância e garantir a estacionariedade dos mesmos. Os retornos foram calculados através da seguinte fórmula, onde $\mathbf{R}_{t}$ é o retorno dos índices, $\mathbf{P}_{t}$ é o fechamento nominal no dia t e $\mathbf{P}_{t-1}$ é o fechamento dos índices no dia $\mathrm{t}-1$.:

\section{1. $\quad \mathbf{R}_{t}=\ln \mathbf{P}_{t}-\left(\ln \mathbf{P}_{t-1}\right)$}

Quando utilizados modelos econométricos para mensurar dados de séries temporais, primeiramente verifica-se se a série é estacionária, pois geralmente, quando se utiliza dados do mercado financeiro, verifica-se que a série não é estacionária. Por estacionariedade entende-se que os dados se distribuem, de forma aleatória, ao longo do tempo, obedecendo a uma média constante. Se os dados da série temporal não forem estacionários poderá gerar tendência na série. Para isso utilizam-se os testes Augmented Dickey-Fuller e PhillipsPerron.

Segundo Durán (2014), séries financeiras apresentam algumas características que são comuns a outras séries temporais, como tendências, sazonalidade, pontos influentes (atípicos), heterocedasticidade condicional e não linearidade. Os retornos financeiros, por outro lado, apresentam outras características peculiares que outras séries não apresentam. Retornos raramente apresentam tendências ou sazonalidade, com exceção eventualmente de retornos intradiários e séries de taxas de câmbio e taxas de juros que podem apresentar tendências que variam com o tempo. Podem-se resumir os principais fatos estilizados relativos aos retornos financeiros:

a. Os retornos são geralmente não autocorrelacionados;

b. Os quadrados dos retornos são autocorrelacionados;

c. Séries de retornos apresentam agrupamentos de volatilidade ao longo do tempo;

d. A distribuição (não condicional) dos retornos apresenta caudas mais pesadas do que uma distribuição normal;

e. Algumas séries de retornos são não lineares (respondem de maneira diferente a choques pequenos ou grandes e a choques positivos e negativos);

O modelo escolhido inicialmente, para análise e tratamento dos retornos, foi o modelo autorregressivo integrado de médias móveis (ARIMA). Como os dados utilizados, tanto os retornos do Ibovespa quanto os retornos do S\&P500, demonstraram ser estacionários, segundo os testes de raiz unitária, não houve a necessidade de integrar os dados e, portanto, o modelo final utilizado foi o autorregressivo de médias móveis (ARMA). O modelo ARMA 
é descrito por seus p valores passados e pelos q ruídos brancos correntes e passados, dados por:

2. $\mathbf{x}_{t}=\boldsymbol{\varphi}_{1} \cdot \mathbf{x}_{t-1}+\ldots+\boldsymbol{\varphi}_{p} \cdot \mathbf{x}_{t-q}+\xi+\boldsymbol{\varepsilon}_{t}-\boldsymbol{\theta}_{1} \cdot \boldsymbol{\varepsilon}_{t-1}-\ldots-\boldsymbol{\theta}_{q} \cdot \boldsymbol{\varepsilon}_{t-q}$

De acordo com Morettin (2004), a construção dos modelos ARIMA é baseada em um ciclo iterativo, no qual a escolha do modelo é feita com base nos próprios dados. Segundo Box e Jenkins (1976). Os estágios do ciclo iterativo são:

a. Identificação: análise de autocorrelações, autocorrelações parciais e outros critérios;

b. Estimação, na qual os parâmetros do modelo identificado são estimados;

c. verificação ou diagnóstico do modelo ajustado: feita através da análise de resíduos, para saber se o modelo é adequado para os objetivos, por exemplo, previsóes.

Caso o modelo não seja adequado, o ciclo é repetido, voltando-se à fase de identificação.

Box e Jenkins (1976) formalizaram a teoria da utilização de componentes autorregressivos e de médias móveis na modelagem de séries temporais utilizando-se de duas ideias básicas na criação de sua metodologia de construção de modelos:

1. Parcimônia, que consiste na utilização do menor número possível de parâmetros para obter uma representação adequada no fenômeno em estudo.

2. Construção iterativa do modelo em que a informação empírica é analisada teoricamente sendo, o resultado deste estágio confrontado com a prática e assim sucessivamente até a obtenção de um modelo satisfatório.

O ciclo iterativo utilizado para a análise de uma série temporal através da metodologia de Box e Jenkins está representado na figura 1 abaixo: 
Figura 1 - Ciclo de Análise da Série Temporal

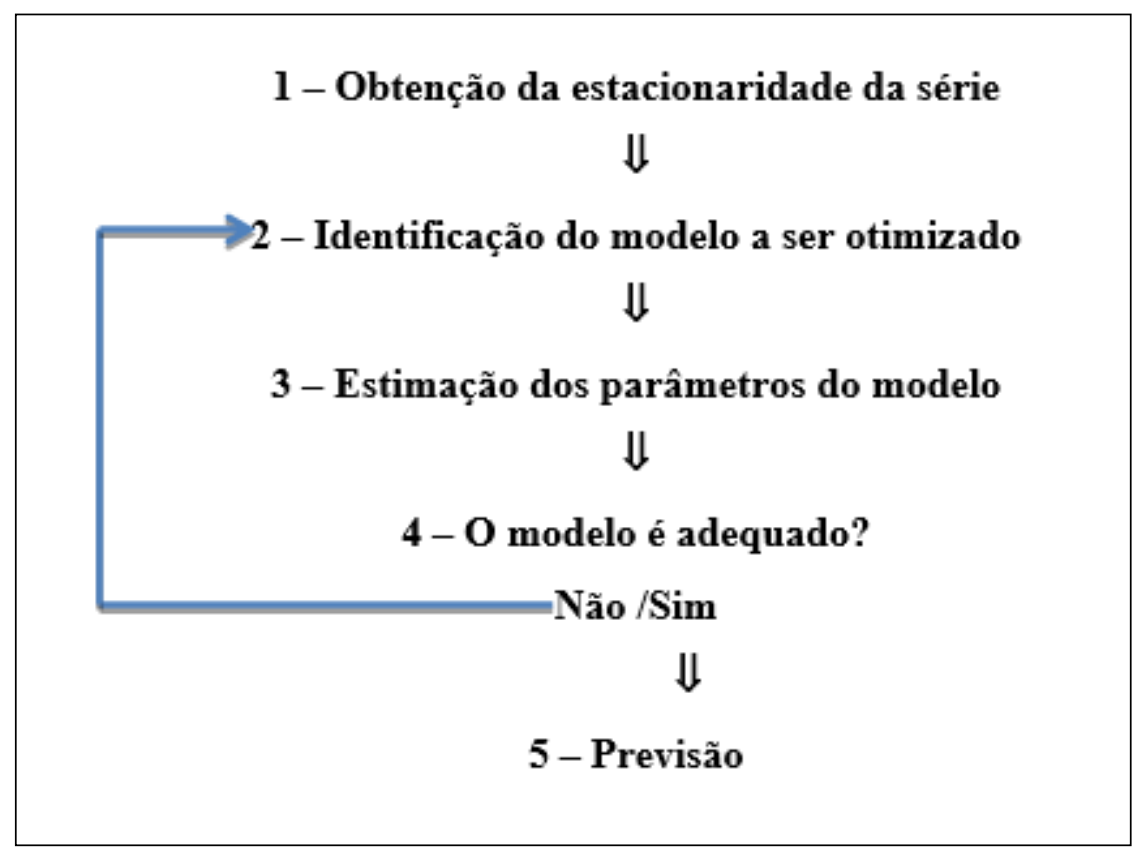

Fonte: Cardoso, 2005.

A partir da série temporal dos retornos do IBOVESPA estimamos as funçóes de autocorrelação e autocorrelação parcial que sugerem um modelo ARMA (1,1). Porém, assim como proposto por Tsay (2002), as funçóes FAC e FACP podem não ser informativas para processos ARMA. Assim, estimamos todas as combinaçóes para p e q identificados a partir das funçóes FAC e FACP e escolhemos o modelo com menor valor para o critério de informação.

Para análise da variância foi utilizado o modelo autorregressivo de heterocedasticidade condicional generalizada (GARCH), o que nos leva a um modelo final ARMA (p, q) -GARCH. Uma generalização do modelo ARCH foi criada por Bollerslev (1986), denominado modelo GARCH (Generalized ARCH), que pôde ser usado para descrever a volatilidade com menos parâmetros do que um modelo $\mathrm{ARCH}$. Neste, são incluídas variâncias passadas no estimador da variância a fim de representar a forte dependência temporal desta variável. O modelo $\operatorname{GARCH}(p, q)$, onde $p$ e $q$ representam a ordem de dependência da variância condicional e dos choques passados pode ser escrito como:

3. $\sigma_{t}^{2}=\alpha_{0}+\alpha_{1} \mathrm{X}_{t-1}^{2}+\ldots+\alpha_{s} \mathrm{X}_{t-s}^{2}+\phi_{1} \sigma_{t-1}^{2}+\ldots+\phi_{r} \sigma_{t-r}^{2}$

Onde $\alpha_{0}>0, \alpha_{1}>0, \phi_{r}>0$ e $\sum_{i=1}^{\max (r, s)}\left(\alpha_{i}+\phi_{i}\right)<1$. Esta última condição garante a estacionariedade de segunda ordem do modelo. 
Esses modelos têm sido amplamente utilizados nos estudos empíricos dos ciclos políticos econômicos nos índices de bolsas de valores (veja, por exemplo, Döpke e Pierdzioch, 2006, já citados $)^{4}$.

Da mesma, forma como feito anteriormente com o modelo ARMA, estimamos todas as combinaçóes para (p) e (q) e identificamos a ordem do modelo GARCH. Segundo Morettin e Toloi (2004), a identificação da ordem de um modelo GARCH, a ser ajustado a uma série real, usualmente é difícil. Recomenda-se que se usem modelos de ordem baixa, como $(1,1),(1,2)$ ou $(2,1)$ e depois se escolha o modelo com base em vários critérios, como AIC e BIC.

Volatilidade é uma peça chave no ambiente financeiro, com um papel significativo em investimentos, na avaliação de títulos, na gestão de riscos e na elaboração de políticas monetárias. Accioly (2016) afirma que, geralmente, uma instituição financeira dedica boa parte de seu tempo de pesquisa à modelagem e à previsão da volatilidade de um ativo. Entre todas as diferentes abordagens para a modelagem de volatilidade, a família GARCH é inequivocamente a mais popular e bem conhecida, provavelmente devido à sua flexibilidade, ao fato de ser facilmente estimada e ao êxito na modelagem de muitos dos fatos estilizados observados nas séries de retornos financeiros, em particular, a presença de clusters de volatilidade.

Para melhorar ainda mais as previsóes da volatilidade GARCH, pode-se incluir variáveis exógenas na equação de variância condicional. Escolhas habituais para regressores incluem volume de negociação, anúncios de notícias macroeconômicas, retornos overnight, volatilidade após fechamento da bolsa, volatilidade implícita dos preços das opçóes e volatilidade realizada.

Para avaliar a presença da influência ciclos políticos econômicos nos retornos e na volatilidade do Ibovespa foram testados os modelos anteriores acrescentado de uma Dummy que assumiu valores 0 e 1 em quatro diferentes períodos. No primeiro modelo, a Dummy 1 assume valor 1 nos seis meses que antecedem as eleiçóes presidenciais e zero nos demais períodos. No segundo modelo, a Dummy2 assume valor 1 no ano que antecede as eleiçóes presidenciais e zero nos demais períodos. No terceiro modelo, a Dummy3 assume valor 1 nos dois anos que antecedem as eleiçóes e zero nos demais meses. No quarto modelo, a Dummy 4 assume valor 1 nos 5 meses antes das eleiçóes até 2 meses antes das eleiçóes e zero nos demais períodos, como podemos observar na figura 2 .

4 Além de Döpke e Pierdzioch (2006), utilizaram o modelo GARCH Koksal e Caliskan (2012) e Azevedo (2012) e o E-GARCH Siokis e Kapopoulos (2007) e Myataza e Gupta (2018). 
Figura 2 - Ciclos políticos e dummies para cada período

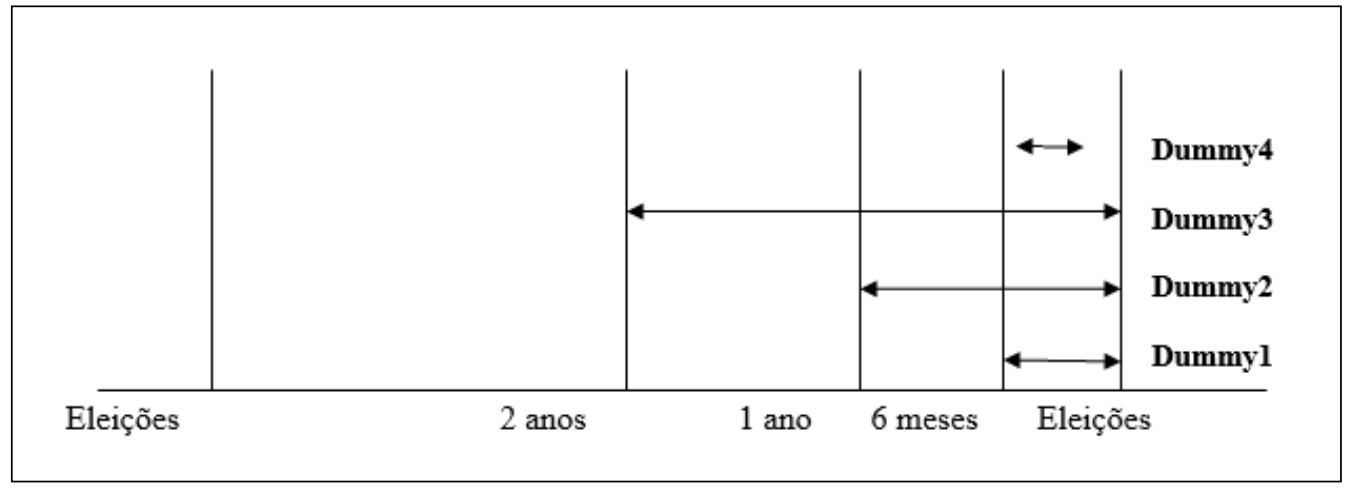

A partir dos motivos expostos, podemos determinar que a equação geral do modelo que irá determinar se há influência dos ciclos políticos econômicos nos retornos e na volatilidade do Ibovespa e que representam os modelos ARMA e GARCH, é a que segue:

4. LogIbovespa $=C+A R(1)+M A(1)+\operatorname{LogS} \& P 500+$ Dummy $_{x}+\mu$

\section{Resultados Econométricos}

Neste capítulo são apresentados os resultados e a análise para os testes e para os modelos de regressão estimados considerando o os retornos do índice IBOVESPA e S\&P500. Ao proceder ao teste de raiz unitária com os dados do modelo, observa-se que as séries são estacionárias para ambos os testes, $\mathrm{ADF}$ e Phillips-Perron, ou seja, ambas variáveis são integradas de ordem zero, I(0). De acordo com os dados do teste Augmented DickeyFuller, onde a série utilizada foi os retornos do Ibovespa, o resultado do p-value foi 0,0000, o que nos permite rejeitar a hipótese nula, evidenciando a presença do estacionariedade da série. O mesmo ocorre com o teste de Phillips-Perron, onde se observou que o p-value é zero, o que também nos permite rejeitar a hipótese nula, evidenciando a presença do estacionariedade da série dos retornos. Os mesmos resultados foram obtidos para série dos retornos do S\&P500, atestando que todas as variáveis são estacionárias. Tanto a tendência quanto o intercepto resultaram em valores estatisticamente náo significativos.

No gráfico 1 tem-se o histograma dos retornos do Ibovespa bem como suas medidas descritivas. A assimetria (skewness), diferente de zero, levemente à esquerda devido ao seu número negativo e a curtose da distribuição dos retornos (Kurtosis), maior que três, é mais achatada do que uma distribuição normal, ou seja, há mais dados nas caudas da distribuição dos retornos do que uma distribuição normal e, portanto, nos mostra que os dados não seguem uma distribuição normal e sim uma distribuição leptocúrtica, o que é importante para selecionar a forma correta de estimar os modelos GARCH. Nesse caso a distribuição de erro a ser utilizada não é a Normal (Gaussiana), mas sim a Student's t. 


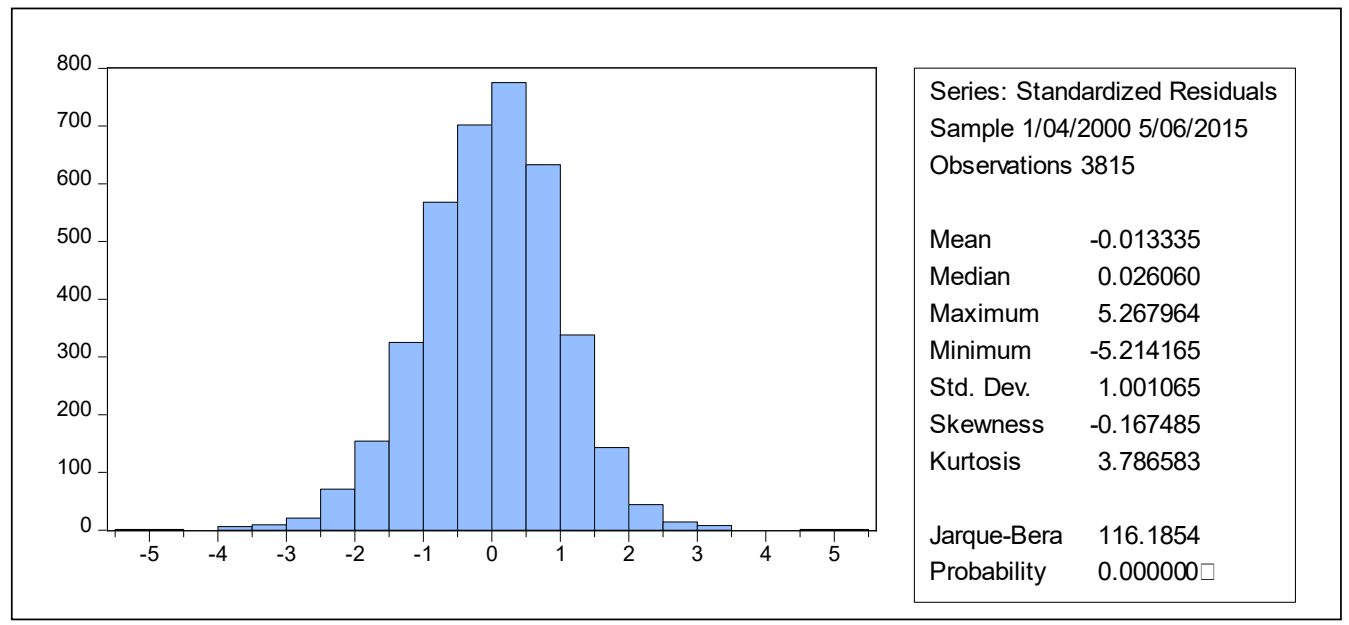

Fonte: resultado de pesquisa, E-views.

Para as regressóes apresentadas na tabela 1, foi realizado o teste Breusch-Godfrey e se confirma que os resíduos de todos os modelos não possuem autocorrelação serial. Os valores encontrados para esse teste foram Obs*R-squared no valor de 1.514602 o que resulta em uma Prob. Chi-Square (1) de 0.4689 , não rejeitando assim a hipótese nula que indicaria a presença de autocorrelação serial dos resíduos. Além disso, obteve-se uma estatística Durbin Watson próximo a 2, que é o nível desejado pois demonstra a ausência de autocorrelação dos resíduos, condição necessária para validação do modelo. Um teste $\mathrm{ARCH}$ adicional, de heterocedasticidade dos resíduos, foi aplicado resultando em Obs*R-squared no valor de 0.091574 e Prob. Chi-Square (1) no valor de 0.7622, não rejeitando a hipótese nula de homocedasticidade dos resíduos. Ao proceder ao teste RESET de Ramsey, para verificar se havia erros na especificação da regressão no que tange a tendência ou inconsistência dos estimadores, não se rejeitou a hipótese nula de que os mesmos possuem media zero e variância constante, pois o resultado F-statistic resultou em um valor de 0.972098 . Utilizando da metodologia de Box-Jenkings identificamos que o índice IBOVESPA é um processo estocástico ARMA $(1,1)$, o que foi incorporado às regressóes dos modelos da tabela.

Com relação aos modelos apresentados na tabela 1 , observa-se que as variáveis dummies não foram significativas para os modelos 1, 2 e 3. Desta forma, os resultados sugerem que não há evidências de que exista influência dos ciclos políticos sobre o retorno médio da IBOVESPA ao longo do período analisado. Considerando o conjunto de modelos apresentados na tabela 1, o modelo (1) é o que apresenta o melhor ajustamento, confirmado pelos critérios de informação ao final da tabela.

Por sua vez, os resultados para o modelo (1) mostram que existe uma forte associação entre o índice que reúne as ações mais negociadas da bolsa brasileira (IBOVESPA) e o SP500, que reúne as açóes de 500 empresas americanas. Ao longo deste período, um aumento de 1\% no SP500 esteve acompanhado de aumento de 0,93\% no IBOVESPA. Considerando apenas os resultados dos modelos da tabela 1 , existe um efeito significativo 
das ações americanas sobre o IBOVESPA, mas não existe uma diferença significativa em termos de retornos médios das açóes da IBOVESPA devido aos ciclos políticos no Brasil.

Tabela 1. Resultados da regressão $\operatorname{ARMA}(1,1)-\mathrm{GARCH}$ para os retornos do índice IBOVESPA por SP500 e Dummy para ciclos econômicos políticos

\begin{tabular}{|c|c|c|c|c|c|}
\hline Variáveis & $(1)$ & $(2)$ & (3) & $(4)$ & (5) \\
\hline $\mathrm{C}$ & $\begin{array}{c}0.000282 \\
(1.561287)\end{array}$ & $\begin{array}{c}0.000352 \\
(1.795942)\end{array}$ & $\begin{array}{c}0.000390 \\
(1.840693)\end{array}$ & $\begin{array}{c}0.000372 \\
(1.420064)\end{array}$ & $\begin{array}{c}0.000269 \\
(1.439228)\end{array}$ \\
\hline LOGSP500 & $\begin{array}{c}0.931185^{* * *} \\
(53.11617)\end{array}$ & $\begin{array}{c}0.930928^{* * *} \\
(52.98004)\end{array}$ & $\begin{array}{c}0.930490^{* * *} \\
(52.86002)\end{array}$ & $\begin{array}{c}0.931682^{* * *} \\
(53.11889)\end{array}$ & $\begin{array}{c}0.929747^{* * *} \\
(52.83082)\end{array}$ \\
\hline $\operatorname{AR}(1)$ & $\begin{array}{c}0.651983^{* * *} \\
(2.874417)\end{array}$ & $\begin{array}{c}0.661542^{* * *} \\
(2.877739)\end{array}$ & $\begin{array}{c}0.664895^{* * *} \\
(2.943961)\end{array}$ & $\begin{array}{c}0.662346^{* * *} \\
(2.895149)\end{array}$ & $\begin{array}{c}0.667153^{* * *} \\
(2.938217)\end{array}$ \\
\hline $\mathrm{MA}(1)$ & $\begin{array}{c}-0.689849^{* * *} \\
(-3.104745)\end{array}$ & $\begin{array}{c}-0.689585^{* * *} \\
(-3.109462)\end{array}$ & $\begin{array}{c}-0.693026^{* * *} \\
(-3.182514)\end{array}$ & $\begin{array}{c}-0.690366^{* * *} \\
(-3.128543)\end{array}$ & $\begin{array}{c}-0.694850^{* * *} \\
(-3.173537)\end{array}$ \\
\hline Dummy 1 & & $\begin{array}{c}-0,000471 \\
(-0.955719)\end{array}$ & & & \\
\hline Dummy 2 & & & $\begin{array}{l}-0,000405 \\
(-1.017807)\end{array}$ & & \\
\hline Dummy 3 & & & & $\begin{array}{c}-0.000168 \\
(-0.467940)\end{array}$ & \\
\hline Dummy 4 & & & & & $\begin{array}{c}0.000181 \\
(0.257604) \\
\end{array}$ \\
\hline $\mathrm{R}^{2}$ & 0,383002 & 0.383169 & 0.383074 & 0.382927 & 0.383039 \\
\hline Durbin-Watson & 1,937837 & 1.938102 & 1.937517 & 1.937540 & 1.937898 \\
\hline Akaike & $-5,819331$ & -5.818570 & -5.818760 & -5.818420 & -5.819130 \\
\hline Schwarz & $-5,804594$ & -5.800558 & -5.800749 & -5.800408 & -5.801119 \\
\hline Hannan-Quinn & $-5,814095$ & -5.812170 & -5.812360 & -5.812020 & -5.812730 \\
\hline
\end{tabular}

A coluna (1) é o modelo $\operatorname{ARMA}(1,1)-G A R C H$. Nas colunas (2), (3), (4) e (5) são os modelos $\operatorname{ARMA}(1$, 1)-GARCH com a dummy 1 , dummy 2 , dummy 3 e dummy 4 , respectivamente. As estatísticas t estão entre parênteses. ${ }^{* *} \mathrm{p}<0,01,{ }^{* *} \mathrm{p}<0,05,{ }^{*} \mathrm{p}<0,10$.

Fonte: resultados de pesquisa, Eviews.

Como próximo passo estima-se um conjunto de regressóes para verificar se existe mudança em termos de volatilidade no índice IBOVESPA por influência dos ciclos políticos no Brasil. Nesta etapa foi realizado o teste de heteroscedasticidade dos resíduos para verificar a presença do efeito GARCH, o que resultou nas informaçóes da tabela 2, confirmando que a volatilidade da série se comporta como um GARCH $(1,1)$. Para os cinco modelos apresentados na tabela 2 , $\operatorname{ARMA}(1,1)-\operatorname{GARCH}(1,1)$, as variáveis dummies consideram a possibilidade de mudança na volatilidade, mantendo os mesmos períodos definidos previamente para variáveis dummy, que torna possível avaliar se existe diferença de volatilidade no índice devido aos ciclos políticos ao longo do período analisado. 
Tabela 2. Resultados da regressão $\operatorname{ARMA}(1,1)-G A R C H$ para a volatilidade do índice IBOVESPA por SP500 e Dummy para ciclos econômicos políticos

\begin{tabular}{|c|c|c|c|c|c|}
\hline Variável & $(1)$ & (2) & (3) & (4) & (5) \\
\hline C & $\begin{array}{c}3.48 \mathrm{E}-06 \\
(5.426623)\end{array}$ & $\begin{array}{c}3.54 \mathrm{E}-06 \\
(5.346154)\end{array}$ & $\begin{array}{c}3.68 \mathrm{E}-06 \\
(5.349767)\end{array}$ & $\begin{array}{c}3.47 \mathrm{E}-06 \\
(5.036622)\end{array}$ & $\begin{array}{c}\text { 3.64E-06 } \\
(5.571537)\end{array}$ \\
\hline LOGSP500 & $\begin{array}{c}-0,000968^{* * *} \\
(-9.046596)\end{array}$ & $\begin{array}{c}-0,000979^{* * *} \\
(-9.067636)\end{array}$ & $\begin{array}{c}-0,000992^{* * *} \\
(-9.030575)\end{array}$ & $\begin{array}{c}-0,001011^{* * *} \\
(-9.025529)\end{array}$ & $\begin{array}{c}-0,000991^{* * *} \\
(-9.077179)\end{array}$ \\
\hline $\operatorname{RESID}(-1)^{\wedge} 2$ & $\begin{array}{c}0.052663 \\
(7.330975)\end{array}$ & $\begin{array}{c}0.052615 \\
(7.331942)\end{array}$ & $\begin{array}{c}0.052773 \\
(7.326286)\end{array}$ & $\begin{array}{c}0.053390 \\
(7.326965)\end{array}$ & $\begin{array}{c}0.052086 \\
(7.346307)\end{array}$ \\
\hline GARCH(-1) & $\begin{array}{c}0,930344^{* * *} \\
(114.0733)\end{array}$ & $\begin{array}{c}0,930333^{* * *} \\
(114.1655)\end{array}$ & $\begin{array}{c}0.929918^{* * *} \\
(113.2870)\end{array}$ & $\begin{array}{c}0,928870^{* * *} \\
(111.5868)\end{array}$ & $\begin{array}{c}0,930747^{* * *} \\
(115.8335)\end{array}$ \\
\hline $\begin{array}{l}\text { Dummy } 1 \\
\text { (GARCH) }\end{array}$ & & $\begin{array}{c}-3.27 \mathrm{E}-07 \\
(-0.486454)\end{array}$ & & & \\
\hline $\begin{array}{l}\text { Dummy } 2 \\
\text { (GARCH) }\end{array}$ & & & $\begin{array}{l}-5.00 \mathrm{E}-07 \\
(-0.922324)\end{array}$ & & \\
\hline $\begin{array}{l}\text { Dummy } 3 \\
\text { (GARCH) }\end{array}$ & & & & $\begin{array}{c}2.96 \mathrm{E}-07 \\
(0.602749)\end{array}$ & \\
\hline $\begin{array}{l}\text { Dummy } 4 \\
(\text { GARCH) }\end{array}$ & & & & & $\begin{array}{l}-1,86 \mathrm{E}-06^{*} \\
(-2.137502)\end{array}$ \\
\hline $\mathrm{R}^{2}$ & 0,383002 & 0.383169 & 0.383074 & 0.382927 & 0.383039 \\
\hline Durbin-Watson & 1,937837 & 1.938102 & 1.937517 & 1.937540 & 1.937898 \\
\hline Akaike & $-5,819331$ & -5.818570 & -5.818760 & -5.818420 & -5.819130 \\
\hline Schwarz & $-5,804594$ & -5.800558 & -5.800749 & -5.800408 & -5.801119 \\
\hline Hannan-Quinn & $-5,814095$ & -5.812170 & -5.812360 & -5.812020 & -5.812730 \\
\hline
\end{tabular}

A coluna (1) é o modelo ARMA-ARCH. Nas colunas (2), (3), (4) e (5) são os modelos ARMA-GARCH como dummy 1 , dummy 2 , dummy 3 e dummy 4 , respectivamente. As estatísticas t estão entre parênteses. ${ }^{* * *} \mathrm{p}<0,01$, ${ }^{* *} \mathrm{p}<0,05,{ }^{*} \mathrm{p}<0,10$.

Fonte: resultados de pesquisa, Eviews.

De acordo com os resultados apresentados na tabela 2, a dummy 4 foi a única significativa, o que nos permite confirmar que há influência dos ciclos políticos econômicos sobre a volatilidade dos retornos do IBOVESPA (a 5\% de significância), embora não sobre a média dos retornos das açóes brasileiras. A diferença de volatilidade que ocorre entre os meses de abril a setembro do ano eleitoral (dummy 4), tendo em vista que o primeiro turno das eleiçóes sempre ocorre no mês de outubro, isso se dá em função da indefinição do possível ganhador do pleito presidencial, o que explica a significância da dummy para este período.

O modelo (5), que considera a dummy 4, embora não seja o melhor ajustado, segundo os critérios de informação, conforme descrito na tabela 2 , é o único que apresenta aumento da volatilidade no período destacado. Neste modelo as ações americanas também possuem uma forte relaçáo com o índice da IBOVESPA. Para cada aumento de $1 \%$ nos retornos das açóes americanas, existe um aumento de $0,93 \%$ nos retornos médios do IBOVESPA.

Modelos adicionais foram testados como o E-GARCH, GARCH-M, TGARCH e PARCH, para comparar os resultados, assim como utilizados em outros trabalhos já citados anteriormente, mas os resultados obtidos com os mesmos foram menos consistentes do que o modelo GARCH. 


\section{Conclusáo}

Os resultados da literatura divergem quanto ao efeito dos ciclos políticos no retorno dos ativos. Em Niederhoffer et al (1970), Riley et al. (1980), Allvine e O’Neil (1980) e Pástor e Veronesi (2017), identificam-se efeitos nos retornos médios das açóes. Pantzalis e Turtle (2000) também chegam no mesmo resultado, mas especialmente para países com menor grau de liberdade de imprensa, política e econômica.

Entretanto, como já mencionado, e de forma coincidente com os resultados do presente trabalho, Siokis e Kapopoulos (2007), Köksal e Caliskan (2012), Azevedo (2012), Döpke e Pierdzioch (2006) e Myataza e Gupta (2018) capturam efeitos advindos dos ciclos políticos sobre a volatilidade das açóes, sem impactos significativos no retorno dos ativos.

Analisando de forma mais detalhada os resultados dos modelos aqui propostos, é possível sugerir interpretaçóes que não apenas enriquecem a percepção de como os ciclos políticos podem influenciar o IBOVESPA, mas também indicam extensóes possíveis ao trabalho.

Ao observarmos os números obtidos nesse estudo e confrontarmos com as teorias de ciclos políticos, a vertente que mais explica os resultados éa Teoria Partidária Racional proposta por Alesina (1998), que parte do princípio que processos eleitorais equitativos tem como particularidade a incerteza quanto o resultado das urnas. A volatilidade significativa aparece em um período compreendido entre 150 e 60 dias da eleição presidencial. Considerando que a eleição presidencial ocorreu em novembro ou outubro, podemos localizar no calendário o período de maior volatilidade entre abril e setembro do ano eleitoral. Dada a fragmentação partidária do sistema político brasileiro, as candidaturas se definem apenas a partir da segunda metade do primeiro semestre do ano eleitoral. Portanto, o período de definição dos candidatos, sem ainda a definiçáo dos programas de governo e principalmente, o fato de não haver pesquisas eleitorais consistentes nesse período, é justamente o momento de maior incerteza, refletida nos nossos modelos, em volatilidade das açóes. Cálculos adicionais foram realizados e não foi encontrado aumento de volatilidade, estatisticamente significativa, nos últimos 2 meses antes das eleições, provavelmente devido a maior definiçãa da intenção de votos dos eleitores, a volatilidade, em média, não demonstrou alteraçóes. Se somarmos a incerteza em relação a quais candidatos irão concorrer à presidência mais a incerteza em relação a quem poderá vir a vencer, teremos um conjunto de fatores fortes o suficiente para justificar o aumento da volatilidade das açóes negociadas em bolsa.

Esta hipótese exposta acima, que procura relacionar a volatilidade com os acontecimentos do período pré-eleitoral relativos a candidaturas e partidos, é possível de ser aventada, mas, com os resultados do trabalho, não se pode avançar além justamente da formulação de hipóteses. Para testa-la, seria fundamental um olhar mais detalhado e comparativo entre o comportamento do IBOVESPA e os acontecimentos de campanha. Mais especificamente, as pesquisas eleitorais poderiam ser usadas como proxy para a expectativa do mercado quanto as probabilidades de vitória de cada candidatura, e estas variáveis construídas seriam, então, relacionadas ao comportamento do principal índice da bolsa de valores de São Paulo. 


\section{REFERÊNCIAS}

ACCIOLY, Victor Bello. Avaliação do Impacto do Realized Range sobre a Volatilidade (E) GARCH: Evidência do Brasil (2016).

ALESINA, A.; SACHS, J. Political Parties and the Business Cycle in the United States, 1948-1984. Ohio State Universety Press, Journal of Money, Credit and Bancking, vol. 20, no 1, p. 63-82, feb. 1988.

ALEXANDER, C. Modelos de mercado: um guia para a análise de informaçóes financeiras. São Paulo: Editora Saraiva, 2005.

ALLVINE, F.C. \& O’Neill, D.E. (1980). Stock market returns and the presidential election cycle. Financial Analysts Journal, 49-56.

AZEVEDO, Vitor Manuel Vieira (2012). Ciclos Político Econômicos no Mercado Bolsista Português. Dissertação (Mestrado em Economia). 46 p. Universidade de Aveiro.

BERGER, Helge e WOITEK, Ulrich. Searching for Political Business Cycles in Germany. Public Choice, v.91, n. 2, p.179-197, 1997.

BOLLERSLEV, T. (1986). Generalized autoregressive conditional heteroskedasticity. Journal of Econometrics, Volume, 31( 3), Pages 307-327.

BOX, G. E. P.; JENKINS, G. M. Time series analysis forecasting and control. San Francisco: Holden- Day, 1976.

CANÇADO, P.L.; ARAUJO JUNIOR, A.F. de. Economics and Politics: O que determina as chances de reeleição em municípios? O caso das eleiçóes municipais de Minas Gerais 2000. Ibmec MG Working Paper - WP26, 2004.

CARDOSO, Mayra Moutinho (2005), Simulação de Modelos GARCH para Séries Temporais Univariadas de Demanda de Energia Elétrica para Consumidores Livres em Regime de Curto Prazo; UNIVERSIDADE FEDERAL DE ITAJUBÁ

CORONADO RAMÍREZ, Semei Lepoldo; ROMERO-MEZA, Rafael; VENEGASMARTÍNEZ, Francisco. Non-Linear Multivariate Dependence between the Mexican Stock Market Index and the Exchange Rate: Efficiency Hypothesis and Political Cycle in Mexico (1994-2012) In: Revista mexicana de economía y finanzas. March 2017 12(1):91-102; Instituto Mexicano de Ejecutivos de Finanzas, A. C., 2017.

DÖPKE, J. \& Pierdzioch, C. (2006). Politics and the stock market: Evidence from Germany. European Journal of Political Economy, 22(4), 925-943.

DOWNS, A. An Economic Theory of Political Action in a Democracy. Journal of Political Economy, v. 65, n. 2, p.135-50, abril de 1957. 
DURÁN, Willian Gonzalo Rojas (2014). Modelo Garch com Mudança de Regime Markoviano para séries Financeiras. Dissertação Mestrado em Matemática e Estatística, Universidade de São Paulo.

ENGLE, R. F. Autoregressive Conditional Heteroskedasticity with Estimates of Variance the Variance of U.K. Inflation. Econometrica, v.50, n.4, p.987-1008, 1982.

FERNANDES, A. M. G. de S., 2009. "Construção de um Índice Sintético para o Mercado Accionista Português: 1977 - 2007”. Dissertação de Mestrado. Universidade Técnica de Lisboa. Instituto Superior de Economia e Gestão.

FOERSTER, S. R. \& SCHMITZ, J. J. (1997). The Transmission of U.S. Electoral Cycles to International Stock Returns. Journal of International Business Studies, 28(1), 1-27.

GUJARATI, D. N. Econometria Básica. São Paulo: Makron Books, 2004

HENSEL, C. R. \& Ziemba, W. T. (1995). United States Investment Returns during Democratic and Republican Administrations, 1928-1993. Financial Analysts Journal, 51(2), 61-69.

HIBBS, Douglas A. Jr. Political Parties and Macroeconomic Policies and Outcomes in the United States. American Economic Review Papers and Proceedings, v.76, n. 2, p.66-70, 1986.

HIBBS, Douglas A. Jr. 1977. "Political Parties and Macroeconomic Policy." American Political Science Review 71 (December): 1467-1487.

HUANG, R.D. (1985). Common stock returns and presidential elections. Financial Analysts Journal , 58-65.

KÖKSAL, B. \& Caliskan, A. (2012). Political Business Cycles and Partisan Politics: Evidence from a Developing Economy. Economics \& Politics, 24(2), 182-199.

MORETTIN, P. A. and T. C. M. (2004). Análise de Séries Temporais. Edgard Blücher, São Paulo.

MYATAZA, A., GUPTA, R. 2018. Political cycles in the United States and stock market volatility in other advanced economies: An EGARCH approach. Journal of Applied Economic Sciences, Volume XIII, Winter, 7(61): 2122 - 2132

NORDHAUS, W. The Political Business Cycle. Review of Economic Studies, v. 42, p.169-90, 1975.

NIEDERHOFFER, Victor et al. Presidential Elections and the Stock Market, Financial Analysts Journal, Vol. 26, No. 2 (Mar. - Apr., 1970), pp. 111-113. 
PANTZALIS, C., STRANGERLAND, D. A. \& TURTLE, H. J. (2000). Political Elections and the Resolution of Uncertainty: The International Evidence. Journal of Banking and Finance, 24(10), 1575-1604.

PÁSTOR, L., and VERONESI, P. 2017. Political Cycles and Stock Returns. Chicago Booth Research Paper No.17- 01, Fama-Miller Working Paper

PREUSSLER, A.P. da S. Um estudo empírico dos ciclos político-econômicos no Brasil. Dissertação (Mestrado em Economia). 97f. Universidade Federal do Rio Grande do Sul, Faculdade de Ciências Econômicas, Programa de Pós-Graduação em Economia, Porto Alegre, 2001.

RECENA, Inácio Gaudie Ley; Ciclos Políticos Econômicos: Um Teste Para os Clubes de Futebol. Dissertação (Mestrado em Economia). 75p. Pontifícia Universidade Católica do Rio Grande do Sul, Programa de Pós-Graduação em Economia, Porto Alegre, 2015.

RIBEIRO; Luiz Cláudio; PAULA, Anaparecida Vieira. Previsão de população através dos modelos ARIMA de Box e Jenkins, 2000 - In: Encontro Nacional de Estudos Populacionais, Anais...: Universidade Federal de Minas Gerais, Caxambu, 2000.

Disponível em: www.abep.nepo.unicamp.br/anais_2000.htm

RILEY, William B. et al. The Market Prefers Republicans: Myth or Reality, The Journal of Financial and Quantitative Analysis, Vol. 15, No. 3 (Sep., 1980), pp.541-560

ROGOFF, Kenneth. Equilibrium Political Budget Cycles. American Economic Review, v. 80 , n.1 , p.21-36, março de 1990.

ROGOFF e SIBERT, A. Elections and Macroeconomic Policy Cycles. Review of Economic Studies, v.55, p.1-16, 1988.

SIOKIS, F. \& KAPOPOULOS, P. (2007) Parties, Elections and Stock Market Volatility: Evidence from a Small Open Economy. Economics \& Politics 19(1), 123-34.

STENGEL, Robert F. Stochastic Optimal Control: Theory and Application. 1.ed. New York: John Wiley \& Sons Inc, 1986.

TSAY, R. S. Analysis of Financial Times Series. New York, Wiley, 2002.

VUCHELEN, J. (2003). Electoral Systems and the Effects of Political Events on the Stock Market: The Belgian Case. Economics and Politics 15(1), 85-102. 